\title{
Modern ferry crossing as an important element in the development of eco-tourism in Sakhalin
}

\author{
Evgeny Kligunov ${ }^{1}$, and Konstantin Pozynich ${ }^{1}{ }^{*}$ \\ ${ }^{1}$ Tikhookeanskiy State University, Tikhookeanskaya st., 136, 680035, Khabarovsk, Russia
}

\begin{abstract}
Adstract. The Sakhalin region and its ecology, natural features and federal reserves with natural ecosystems, has a high potential in ecotourism, and therefore the problems of operating bridge span structures of the ferry crossing connecting the island with the mainland are becoming increasingly important. This is due to the fact that the traffic flow at the ferry crossing, including off-farm transportation of agricultural goods, has increased significantly. Consequently, the load on the bridge structures has increased. In addition, natural factors play a significant role in the operation of the structures. Therefore, the issue of the durability of bridges has several generalized components, including the mechanical wear along with moral and physico-chemical wear. The paper deals with the topic of the correct and uniform distribution of high load bearing between structural elements of large-span structures, since under the influence of the natural gravity of the structure and the influence of external factors, dangerous damage can occur. As a research task, the authors determined an attempt to assess the load of the lifting mechanisms located on the abutments of the intermediate supports and serving to set the spans in the required position. In case of increase in the mass of spans, overcoming the resulting imbalance can lead to a noticeable increase in the required power of the drive of the mechanisms.
\end{abstract}

\section{Introduction}

\subsection{Formulation of the problem}

Ferry crossings, which have a number of advantages, are divided into rail, road and combined (road-rail). Ferries can be cargo, passenger and passenger-and-freight. Modern railway ferry crossings are passenger-and-freight and combined (car-rail). Onshore facilities of ferry crossings (Fig. 1) are technically complex complexes that include, as a rule, railway and road transport facilities, maintenance and management infrastructure.

\footnotetext{
* Corresponding author: 000400@pnu.edu.ru
} 


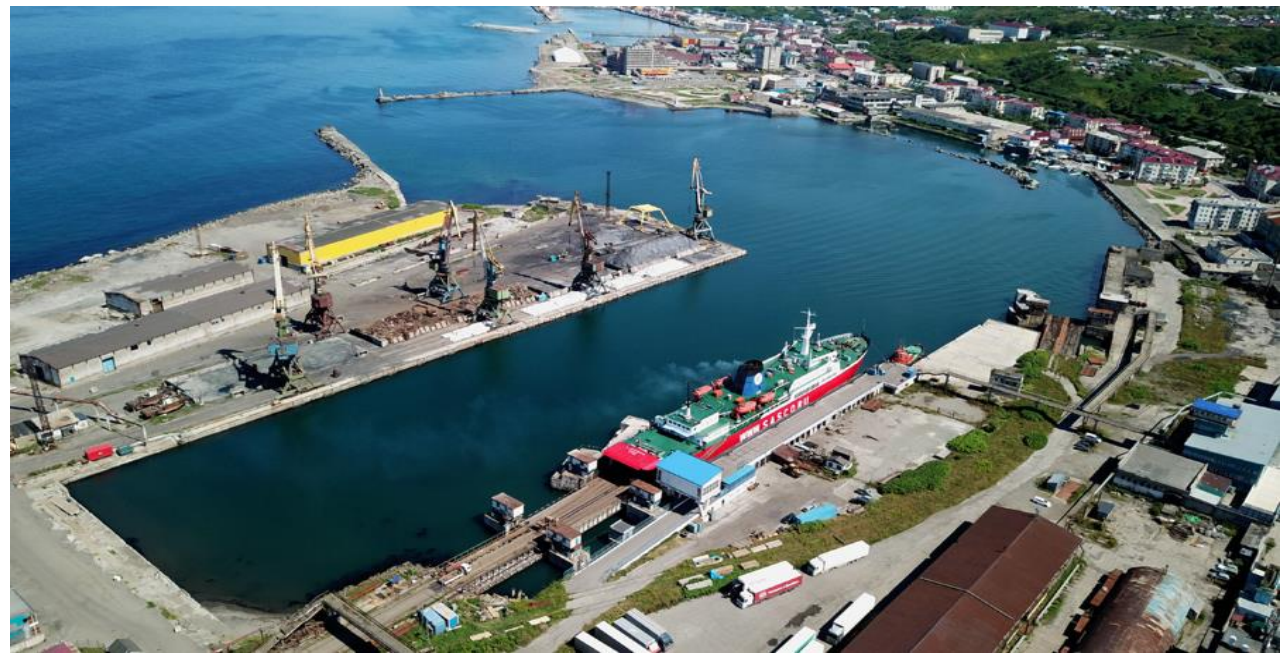

Fig. 1.. General view and relative position of onshore facilities of the sea ferry.

One of the main structural elements of ferry crossings are the linkspans, providing the connection of ferries with access routes. The design of the linkspans at each crossing differs due to the processing of either different types of ferries or local conditions. Fundamental technical solutions of railway crossings from the moment of their occurrence have not changed. Two types of crossings can be distinguished: those working at a short distance (river), and those working along a long sea route (at least $100 \mathrm{~km}$ ).

Improving the operational reliability and transport and operational status of bridge structures seems to be an urgent task [1-7].

The automobile-railway linkspan (Fig. 2) is a water-transporting special hydraulic structure of a sea ferry crossing. Linkspans provide possibility of sea ferries loading with wagons with goods and cars. Ferry loading is carried out by supplying cars from the marshalling yard through linkspans with automated regulation of the exit height of the wagons to adjust to the draft of the vessel.

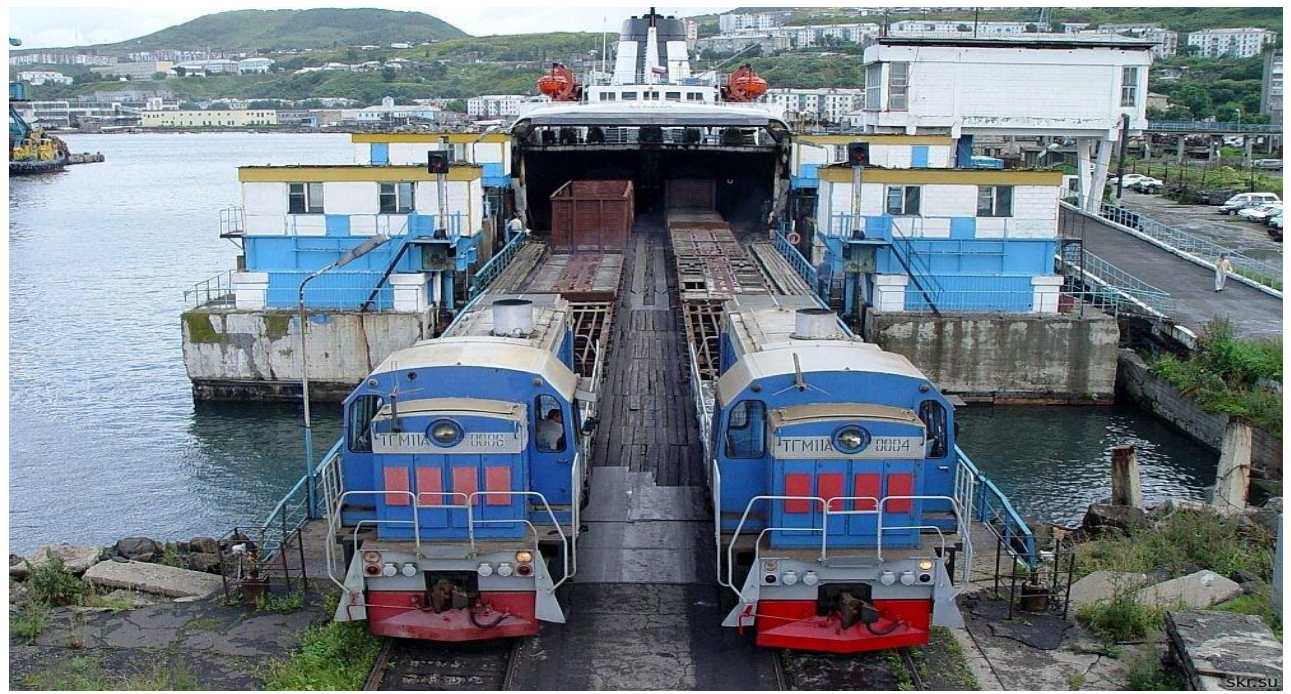

Fig. 2. The automobile-railway linkspan 
The linkspan consists of two spans: shore and marine, coupled in conjunction with each other. In addition, the coastal span has two support systems also (one on each side of the bridge) - intermediate with helical hoisting mechanisms and marine with lifting hoists. Lifting mechanisms allow you to change the height position of the ends of the spans and their slopes, in accordance with the wagon deck at the stern of the ferry. This mark depends on the draft of the ferry at its different loading, as well as on sea level.

The shore span at one end is articulated on the shore abutment. Between the abutment and the end of the span, shock absorbers are installed that absorb horizontal forces caused by the action of the ferry and railway rolling stock on the bridge. At the other end, this span structure through a lifting beam in conjunction with spans using counterbalanced devices and lifting screws is suspended to metal superstructures on towers of intermediate supports.

The marine span at one end rests on a special lifting beam in conjunction with spans, and at the other end, during rolling up and rolling out of the wagons to the stern of the ferry. The suspension of the span to the towers of the marine supports is carried out in a point at a certain distance from the sea end of the span through a special span beam. If there is a temporary load on the sea span structure, its statistical structure is a beam on two supports, in the absence of a temporary load on the span, its statistical structure has a load according to the single-beam structure.

The roadway of the bridge provides for the passage of two railway tracks of $1524 \mathrm{~mm}$ gauge, as well as automobile and tracked vehicles with a speed limit of up to $5 \mathrm{~km} / \mathrm{h}$. For the passage of rail transport between rails, a continuous longitudinal flooring of wooden beams is arranged, creating a driving bed. On both sides there are sidewalks with plank flooring, fenced with metal railings. The sea span has two turnouts, providing branching of the tracks into four gauges, respectively, of the ferry gauges.

For the linkspan, which is characterized by a number of specific features, one significant factor is characteristic: constant contact with water. Moreover, regardless of what the structure contacts (seawater, fresh water, groundwater or sewage), the aquatic environment is aggressive towards the materials of which it is built. Water has a mechanical, physical, chemical and biological effect on them. Regardless of the structures and materials, the linkspan axles are the most loaded, subject to the effects of general and local many times repeated dynamic temporary environmental loads (temperature, water, ice, insolation, etc.) and salts.

All these types of influences lead to premature destruction of the structures of the hydraulic structure [8-12]. So, according to published data, according to the results of the inventory, at present, most of the hydraulic structures of Russia (more than 52\%) are in a state requiring major repairs. The average age of retaining dams, dykes and other hydraulic structures is 30-40 years, and in some cases exceeds 100 years. In addition, in Russia, hydro-technical facilities are characterized by a rather low level of safety. The vast majority of hydraulic structures is in need of maintenance.

\section{Materials and methods}

Let us consider in more detail the Vanino-Kholmsk ferry complex (ferry crossing), built in 1973, which is one of the main transport corridors for delivering goods from the mainland to Sakhalin Island and today needs urgent repair and restoration works.

The global reconstruction of the crossing is planned for 2019-2021.

The two-span linkspans of the Vanino-Kholsk ferry crossing are designed according to the scheme with freely moving counterweights (Fig. 3). 
a)
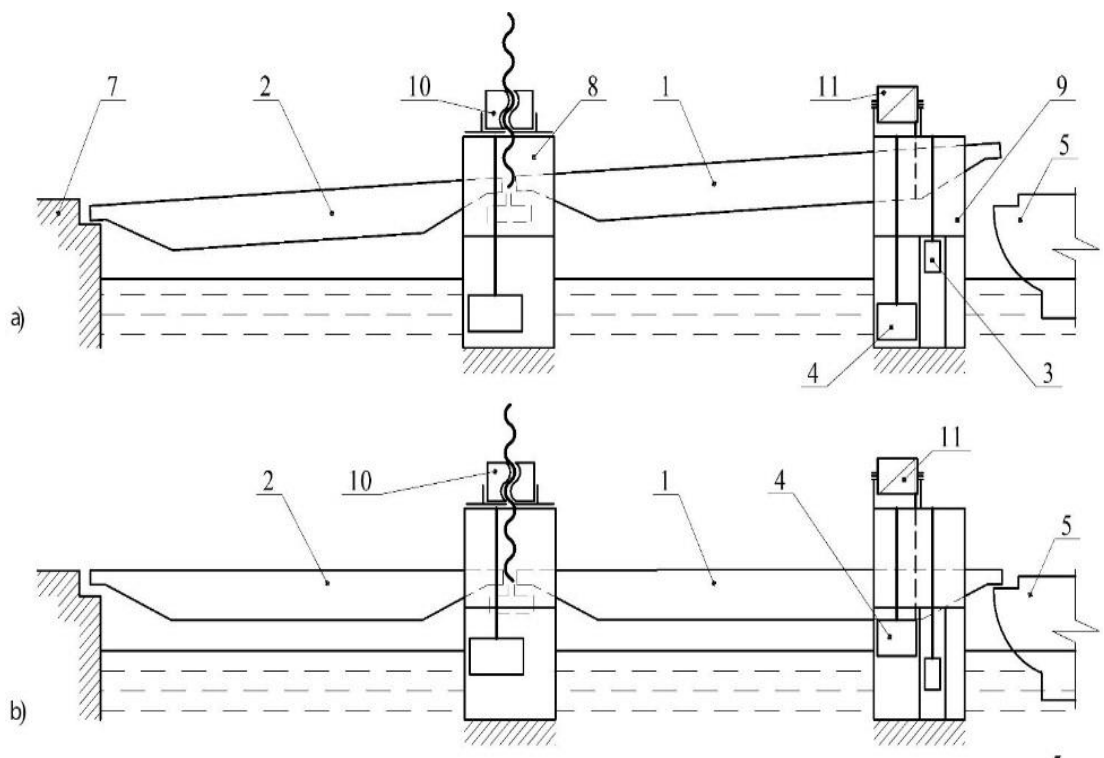

b)

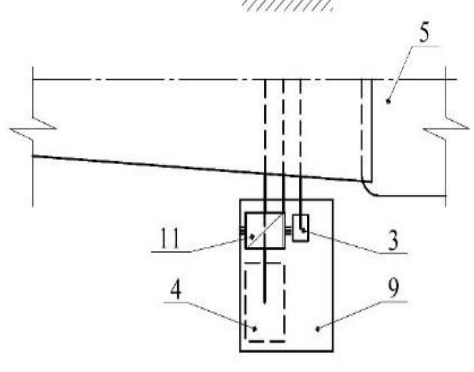

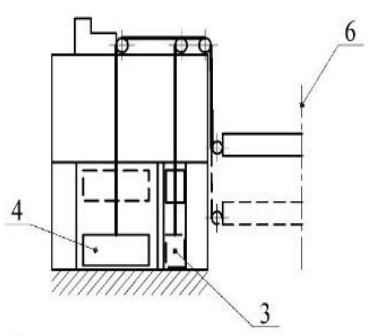

c)

d)

Fig. 3. Linkspan of the ferry in the seaport of Kholmsk: longitudinal sections respectively, in nonworking (a) and working (b) positions, a transverse section along the axis of the lifting beam of the sea span (c) and plan (d): 1 - sea span structure; 2 - shore superstructure; 3 - counterweight lifting mechanism; 4 - the main counterweight; 5 - ferry; 6 - plane of symmetry of the linkspan; 7 - shore support; 8 - intermediate support; 9 - sea support; 10 - screw lifting mechanism on an intermediate support; 11 - winch lifting mechanism of the sea support

According to the plan, in the sea harbors in both ports, berth complexes will be modernized, shore facilities for receiving new ferries will be repaired so that by the time the new ships are delivered, the port infrastructure will meet all the necessary requirements. During the reconstruction, it is planned to carry out dredging works up to 10 meters - today they are $8.5 \mathrm{~m}$. The project also provides for the complete replacement of two linkspans, piers and racks lengthening, concreting at a variable level, fenders replacing, communications replacing.

A rope-block suspension system of a linkspan and the arrangement of lifting mechanisms is presented on fig. 4 .

The main purpose of the bridges is to provide the possibility of transferring trains from coastal routes to ferries and / or vice versa at a constantly changing difference in their marks, which depends on the position of the sea level and the subsidence of the stern of the vessel at different intensities of moving loads 


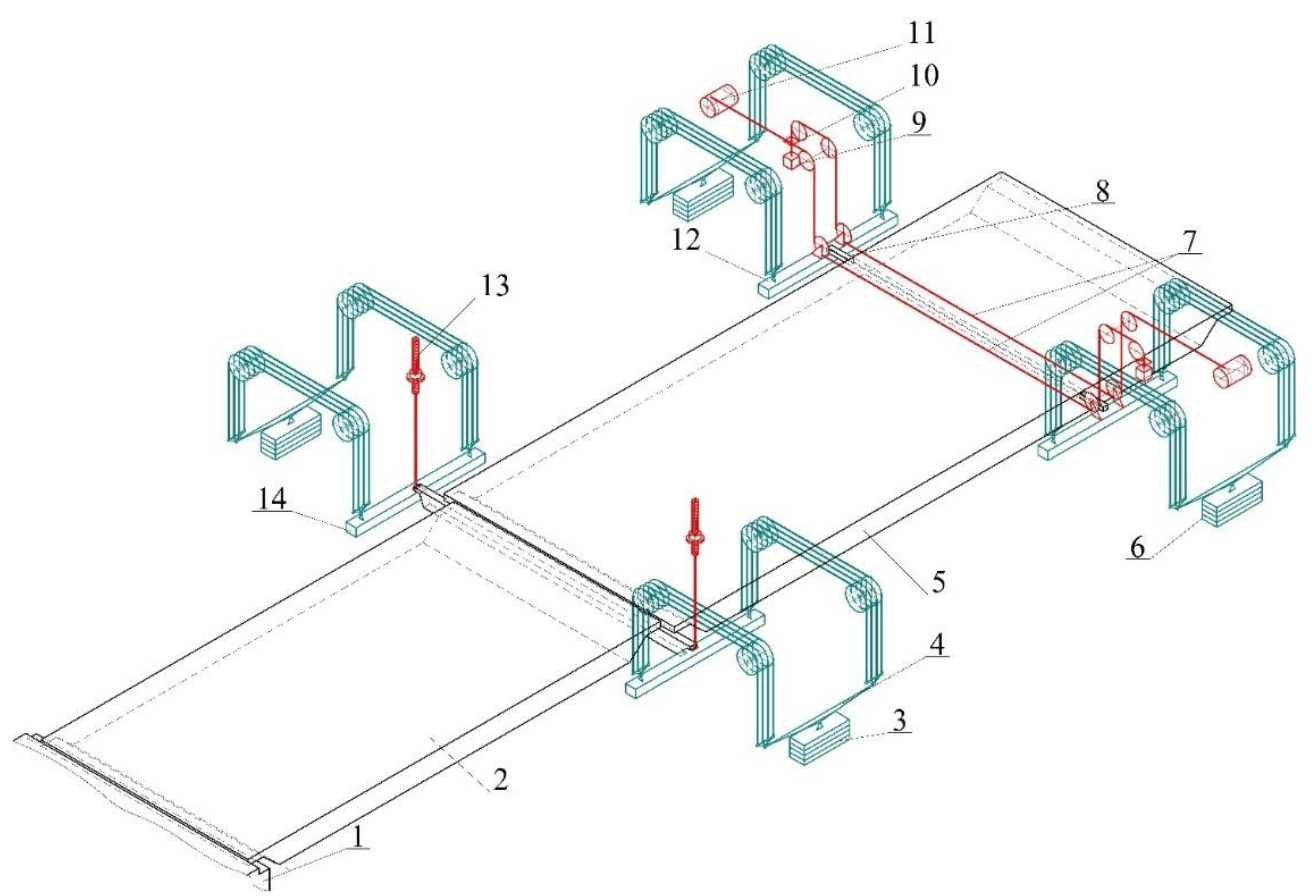

Fig. 4. Rope-block suspension system of overhead structures of a linkspan: 1 - shore support No. 1; 2 - shore superstructure; 3 - counterweight intermediate support No. 2; 4 - balancing device of the counterweight; 5 - sea span; 6 - counterweight of the sea support No. 3; 7 - lifting ropes of a sea support No. 3; 8 - lifting beam No. 3; 9 - operative counterweight; 10 - shock absorber; 11 - lifting winch of a sea support No. 3; 12 - traverse beam of the sea support No. 3;13 - screw lifting mechanism of the intermediate support No. 2; 14 - traverse beam of the intermediate support No. 2

The hoisting mechanisms available as part of the onshore structures located on the abutments of the intermediate support (vertical propellers) and on the abutments of the sea support (electric hoists) ensure the installation of spans in the required position. Over more than forty years of operation, routine technical inspections of the condition of structures and devices of the linkspan were carried out and maintenance was carried out. One of the main tasks in this case was the maintenance of the load established by the project for the own weight of the sea span, perceived by lifting gears, at the level of $61-111 \mathrm{kN}$ due to the adjustment of the weight of the main balances. At the same time, scheduled preventive and major repairs to eliminate critical defects that significantly reduced the operational characteristics of the metal structures of the superstructures of the lifting-transition bridge, and repairs of the lifting mechanisms, were not carried out.

As a result of the reasons stated above, under continuous operation, the metal structures of the linkspan underwent significant corrosion wear, as a result of which the carrying capacity of the longitudinal beams decreased by $80 \%$, and the transverse beams by $5-15 \%$ of the design load. Thus, the carrying capacity of the marine span has become insufficient to absorb the loads from the rolling stock (load class is higher than the beam class), i.e. a reduction in gross rail weight and axle load is required.

\section{Results}

Proposals were developed that made it possible to carry out work in the shortest time and without interruption in the supply of vital goods for the island of Sakhalin Oblast to ensure 
the safe operation of the ferry crossing before its global reconstruction began. So, from October 2018, in order to ensure uninterrupted transportation during the period before the reconstruction of ferry complexes, it was decided to begin urgent repair and restoration work on the Vanino-Kholmsk ferry crossing bridge at the seaport of Kholmsk in the amount performed in the time "window". This order of works production optimizes the pace of work and their safety. The purpose of these works is to strengthen the elements of spans while maintaining the design capacity of the structure. Under this option, the following main types of work are provided:

- cleaning of metal structures of spans and lifting beams;

- cutting of transverse ribs;

- reinforcement of the walls of the main span beams and lifting beams with metal plates;

- arrangement of new longitudinal and transverse ribs;

- painting of metal structures;

- arrangement of a new roadway, followed by a protective impregnation.

Since the accepted repair option implies the strengthening of the elements of spans with the addition of overlays and ties, as a result, the mass of spans and, consequently, the magnitude of the imbalance of spans increases significantly.

In order to determine the load changes $\Delta R_{s}$ at the suspension points of the sea span caused by a change in the weights of the sea span and its lifting beams (shown in Fig. 4), we compiled the design diagram shown in Fig. 5. At point $\mathrm{C}$ in the diagram, the span is supported on the stern of the ferry, while the span $\mathrm{AC}=33.4 \mathrm{~m}$. Point $\mathrm{B}$ is the suspension point of the span. The following assumptions were made:

- resultant change in weight of the sea span structure $\Delta R_{\text {s.sp.st. is applied at the middle part }}$ of the span;

- the resultant change in the weight of the lifting beam $\Delta R$ I.b. passes through the axis of the counterbalance wells.

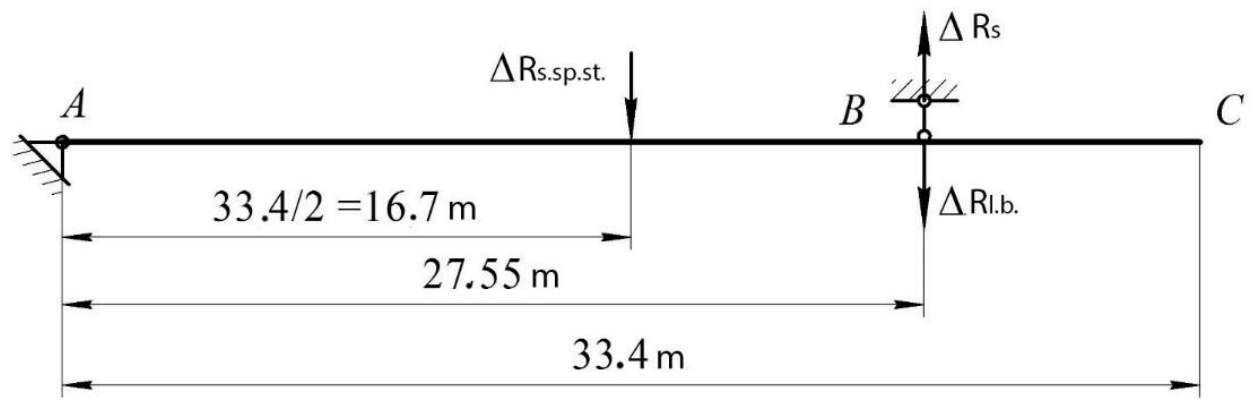

Fig. 5. The design scheme for determining the lack of balance of the sea span.

In this case, the amount of imbalance is the force acting on the stern of the ferry.

The imbalance from its own weight (namely the advantage) is a necessary phenomenon, because it acts in the direction of the span and ensures a tight fit of the span to the supporting parts in the lowered position, and also helps to ensure the stability of the span structure, which rotates relative to the hinge.

When planning emergency repair work on the linkspan, it was envisaged to increase the weight of the sea span by 30.48 tons and the lifting beam of the span by 2.05 tons, which, naturally, would lead to an increase in unbalance on the sea support by $20.53 \mathrm{t}$. At the same time, on each of the two suspension points of the sea span according to Fig. 3 will additionally account for 10.26 tons. Accordingly, this will necessitate an increase in the mass of the main counterweights on the sea support to maintain the design magnitude of the imbalance, which will require large material and time costs. 
It is obvious that it is not advisable to overestimate the amount of imbalance compared with the project, as this will affect, among other things, the power characteristics of the drive of the lifting mechanism, which is also in operation for a long time.

This circumstance led to the need to perform a large volume of verification calculations of the installed lifting mechanisms (electric hoists), elements of the rope block systems of the span structure, suspension elements of the main balances, etc.

\section{Conclusion}

After our verification calculations of lifting mechanisms, suspension of the span structure and counterweight devices on the possibility of their use after repair of the linkspan in connection with the increase in its mass, it was found that:

- ropes of the lifting mechanism and counterweight devices provided in the project, as well as currently used after replacement, satisfy the strength condition;

- electric drives of the lifting mechanisms of the sea support have sufficient power to lift the span with design speeds at an acceptable start time;

- the brake of each lifting mechanism provides sufficient braking torque;

- the strength of the axes of the guide blocks of the cable-block systems is ensured;

- load bearing capacity and durability of block bearings is ensured.

Thus, the operation of lifting mechanisms, suspension elements of the superstructure of the lifting-transition bridge and counterweight devices in case of increase the mass of the marine superstructure after repair is possible without changing (increasing) the weight of the main counterweights and replacing the elements of the lifting mechanisms and counterweight devices.

However, guided by the rules for the technical operation of the ferry, and taking into account the long excess service life of the hydraulic structure and, in particular, the lifting mechanism on the sea support, as well as the possible decrease in the strength of its elements and parts due to accumulated deformations and material fatigue, it seems appropriate to reduce the load on the drive of the lifting mechanism by increasing the mass of the main counterweights on the sea support.

The maximum permissible mass of one counterweight of the sea support, according to our calculations, is 82.35 tons. According to the project, two main counterweights weighing 76 tons each were installed on the sea support, i.e. the increase in mass of one counterweight on the sea support will be 6.35 tons.

\section{References}

1. C. Liu, Zh. Jiang, H. Yu, Measurement, 151, 107169 (2020) https://doi.org/10.1016/j.measurement.2019.107169

2. V.K.R. Kodur, M.Z. Naser, Journal of Constructional Steel Research, 156, 46-53 (2019) https://doi.org/10.1016/j.jcsr.2019.01.020

3. G. Alencar, A. de Jesus, J. Guilherme, S. da Silva, R. Calçada, Engineering Failure Analysis, 104 154-176 (2019) https://doi.org/10.1016/j.engfailanal.2019.05.037.

4. S.-N. Andersen, T. Tørset, Case Studies on Transport Policy, 7(3), 667-676 (2019) https://doi.org/10.1016/j.cstp.2019.04.006

5. J. Bogunovic-Jakobsen, Journal of Wind Engineering and Industrial Aerodynamics, 69-71, 795-805 (1997) https://doi.org/10.1016/S0167-6105(97)00206-7 
6. D. Milne, L. Le Pen, G. Watson, D. Thompson, W. Powrie, M. Hayward, S. Morley, Transportation Geotechnics, 17(A), 61-68 https://doi.org/10.1016/j.trgeo.2018.09.002

7. F. Marques, C. Moutinho, W. Hu, Á. Cunha, E. Caetan, Engineering Structures, 123, 15-29 (2016) https://doi.org/10.1016/j.engstruct.2016.05.016

8. H. Ma, Zh. Zhang, B. Ding, X. Tu, Construction and Building Materials, 191, 679-691 (2018) https://doi.org/10.1016/j.conbuildmat.2018.10.056

9. E. Van Puymbroeck, W. Nagy, H. de Backer, Procedia Structural Integrity, 13, 920925 (2018) https://doi.org/10.1016/j.prostr.2018.12.173

10. A. Dinas, Th.N. Nikolaidis, C.C. Baniotopoulos, Procedia Environmental Sciences, 38, 578-585 (2017) https://doi.org/10.1016/j.proenv.2017.03.131

11. T. Plachý, M. Polák, P. Ryjáček, Procedia Engineering, 199, 3053-3058 (2017) https://doi.org/10.1016/j.proeng.2017.09.555

12. J. Leander, D. Honfi, O. Larsson-Ivanov, Í. Björnsson, Engineering Failure Analysis, 91, 306-314 (2018) https://doi.org/10.1016/j.engfailanal.2018.04.033 